\begin{tabular}{|} 
Ambiente \& Água - An Interdisciplinary Journal of Applied Science \\
ISSN 1980-993X - doi:10.4136/1980-993X \\
www.ambi-agua.net \\
E-mail: ambi.agua@gmail.com
\end{tabular}

\title{
Monitoramento da água de poços como estratégia de avaliação sanitária em Comunidade Rural na Cidade de São Luís, MA, Brasil
}

\author{
doi:10.4136/ambi-agua.1962
}

Received: 30 Jun. 2016; Accepted: 01 Dec. 2016

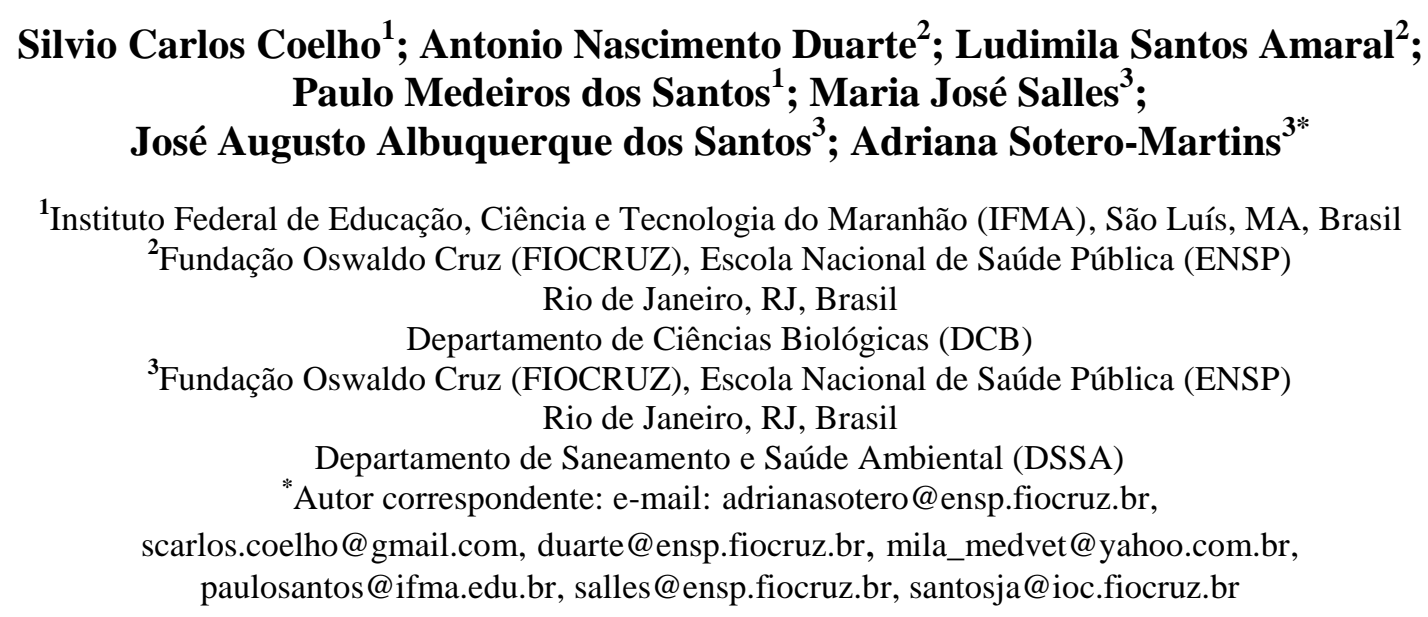

\section{RESUMO}

Como ações de saneamento são escassas ou inexistentes no meio rural, o monitoramento das fontes de água permite o diagnóstico dos riscos e da precariedade das situações de saneamento. Neste estudo foi monitorado sazonalmente a qualidade da água dos poços da comunidade rural "Cinturão Verde" por meio de análises físico-químicas, colimétricas, e parasitológicas para identificação de fontes de contaminação devido à ausência de meios adequados de saneamento. Foram analisadas amostras coletadas em quatro períodos sazonais e detectados coliformes acima dos padrões de potabilidade do Ministério da Saúde nos poços tubulares em três dos quatro períodos sazonais. Foi detectada também a presença de parasita no período seco. Os parâmetros físico-químicos também estavam fora dos padrões da legislação em algumas estações, e foi constatado que esses riscos eram devido à inexistência de serviços de saneamento como: abastecimento com poços sem tratamento, precariedade de esgotamento e proximidade dos mananciais à criação de animais. Conclui-se que o monitoramento permitiu detectar períodos de riscos no uso de águas dos poços, avaliar diferenças regionais, e a necessidade de medidas de desinfecção da água antes de ser utilizada. Estas medidas de saneamento rural podem garantir a proteção dos mananciais de águas subterrâneas.

Palavras-chave:águas subterrâneas, qualidade sanitária, saneamento, saúde ambiental.

\section{The monitoring of water wells as health evaluation strategy in Rural Community in São Luís City, MA, Brazil}

\begin{abstract}
As sanitation is scarce or nonexistent in a rural environment, the monitoring of water sources allows for the diagnosis of risks and precarious sanitation situations. This study
\end{abstract}


seasonally monitored the water quality of wells in the rural community of Cinturão Verde by means of physical and chemical analysis and colimetric and parasitological assays, and identified sources of contamination due to the lack of adequate sanitation. Samples collected in four seasonal periods detected levels of coliform in wells above the potability standards of the Health Ministry in three of the periods, and detected the presence of parasites in the dry season. Physical and chemical parameters also exceeded legal standards in some periods, and it was found that these risks were due to lack of proper sanitation practices, such as water supplied by untreated wells, improper drainage and the proximity of water sources to livestock. Water monitoring enabled the detection of risk periods when using well waters, the evaluation of regional differences, and the showed the need for water disinfection before use. These rural sanitation measures can help to ensure the protection of groundwater sources.

Keywords: groundwater, environmental health, sanitation, sanitary quality.

\section{INTRODUÇÃO}

A interface do saneamento com a qualidade de vida e a saúde pressupõe um ambiente saudável. Ações inerentes ao saneamento são pouco intensas no meio rural, geralmente composto somente pelo abastecimento de água (nem sempre potável) coleta e disposição final dos resíduos sólidos e sistema de esgotamento sanitário precário. Como esses fatores atuam promovendo a salubridade ambiental, no meio rural os riscos relacionados à precariedade do saneamento são mais evidentes (Daniel, 2001; Amaral et al., 2003; Costa e Guilhoto, 2014). Em locais com saneamento básico deficiente, as doenças de veiculação hídrica podem ocorrer devido à contaminação da água por dejetos ou pelo contato com esgoto despejado nas ruas ou nos córregos e rios. A falta de água também pode causar doenças, pois a escassez impede a higiene adequada. E ainda inclui-se a proliferação de insetos que se desenvolvem na água (CVE, 2009). As principais doenças relacionadas à ineficiência e/ou inexistência dos serviços de saneamento são causadas principalmente por microrganismos patogênicos de origem entérica, animal ou humana (Amaral et al., 2003).

O acesso à água potável tem impacto no desenvolvimento socioeconômico, e segundo a Organização das Nações Unidas (ONU) é um direito humano essencial, intrinsicamente relacionado com o direito à vida, à saúde e à alimentação. Há evidências de que o gasto com medidas de saneamento é mais eficaz do que os gastos com saúde, principalmente em relação ao acesso a água de qualidade e tratamento de esgoto. Os investimentos em saneamento acarretam a diminuição de casos de morbidade e de internações hospitalares (Caldeira, 2014). Portanto, cabe ao Estado a responsabilidade de assegurar esse direito a todos os cidadãos, sobretudo aqueles em situação de vulnerabilidade socioambiental, como a população da zona rural (Heller e Pádua, 2006). Portanto o saneamento é um instrumento de promoção e de melhoria da saúde, como determinado pela Lei de Saneamento No. 11.445/2007. Essa Lei estabelece um conjunto de serviços, infraestrutura e instalações operacionais de abastecimento de água potável, esgotamento sanitário, manejo de resíduos sólidos, drenagem e manejo de águas pluviais urbanas (Brasil, 2010).

Ações adequadas de saneamento rural promovem a salubridade ambiental e contribuem para diminuição da degradação do ambiente e da exploração de forma insustentável dos recursos naturais. Para isso, medidas planejadas, em especial as que garantam a proteção dos mananciais de água doce, com a disposição adequada do esgotamento sanitário e dos resíduos sólidos são fundamentais (Costa e Guilhoto, 2014; Brasil, 2006).

A qualidade da água no ambiente é função do uso e da ocupação do solo na bacia hidrográfica onde o manancial se encontra. Essa qualidade é influenciada pelos seguintes fatores: condições naturais, que podem afetar o escoamento superficial; infiltração no solo, 
resultantes da precipitação atmosférica; atuação do homem, interferindo com a geração de despejos domésticos, industriais, e de criação de animais; e a aplicação de defensivos agrícolas no solo, que de diversas formas contribui com a introdução de compostos na água. Esses fenômenos de poluição apresentam riscos à saúde e comprometem um ou mais usos dos mananciais com a perda de qualidade devido a alterações em suas características (Brasil, 2006).

A identificação dos microorganismos patogênicos na água é geralmente complexa e onerosa. Por essa razão, tradicionalmente se recorre à identificação de organismos indicadores de contaminação, como por exemplo, organismos cuja presença apontaria a introdução de material de origem fecal (humana ou animal) na água, e, portanto, o risco potencial da presença dos organismos patogênicos. Os bioindicadores tradicionais para esse fim são as bactérias do grupo coliforme (coliformes totais e coliformes termotolerantes) e a espécie de bactéria Escherichia coli (Sotero-Martins et al., 2013). As águas subterrâneas apresentam menos restrição de uso in natura em relação às águas superficiais, pois as camadas do solo servem como filtros naturais eliminando contaminantes (Herráiz, 2009). Contudo, para fins de abastecimento humano, a água precisa passar por um processo de desinfecção, como preconiza a Portaria do Ministério da Saúde (MS) No. 2.914/2011, que estabelece os padrões de potabilidade e também define os teores toleráveis de certas impurezas, e a Resolução do CONAMA No. 368 de 3 de abril de 2008 que trata sobre o uso de águas subterrâneas (Hager, 2007).

Devido aos riscos associados ao consumo de água contaminada, é indispensável o tratamento da água para consumo humano e uso na agricultura, que tem por finalidade inicial, torná-la potável. Portanto, os principais objetivos do tratamento são de ordem sanitária (remoção e inativação de organismos patogênicos e de substâncias químicas que apresentam risco a saúde) e estética organoléptica (remoção de turbidez, cor, sabor e odor) (Brasil, 2006). Os métodos que podem ser empregados no tratamento da água com objetivo da desinfecção que não é a eliminação total dos microrganismos, mas sim diminuir a população de patógenos (Gonçalves et al., 2003) - são os métodos químicos, biológicos, físicos e/ou fotoquímicos (Tchobanoglous et al., 2003; Archer et al., 1997; Von Sperling et al., 2003). A principal forma de desinfecção química utilizada é a cloração, que é um processo químico que utiliza o cloro (Aisse et al., 2003). Contudo, o método físico altamente recomendado para áreas desprovidas de recursos é a fervura da água para beber, quando a sua qualidade não merece confiança e em épocas de surtos epidêmicos ou de emergência. Para minimizar o sabor desagradável que fica após o processo, deve-se agitar a água para que o ar penetre em sua massa (Medeiros Filho, 2009).

Neste sentido, o objetivo deste trabalho foi realizar o monitoramento sazonal da qualidade da água de poços tubulares da comunidade rural "Cinturão verde" de São Luís MA, e identificar prováveis fontes de contaminação do solo e da água subterrânea, decorrentes da ausência de meios adequados de saneamento.

\section{MATERIAL E MÉTODOS}

O estudo foi do tipo descritivo e exploratório, com coleta de amostras de água nos poços tubulares, realizadas em quatro regiões da Comunidade Cinturão Verde, localizada na área rural a sudoeste da Ilha de São Luís - MA, no município de São Luís, na microbacia do Tibirí, entre as coordenadas 585160 E - 9706768 S; 586475 E - 9708085 S; Sistema de Projeção: UTM SIRGAS 2000 Zona 23 S - datum: D SIRGAS 2000. Esta comunidade tem como principal atividade a produção de hortaliças, legumes e frutas próximo a um aterro sanitário, conta com oitenta domicílios, num total de 342 pessoas. As amostras foram coletadas nos quatro poços artesianos ativos, que possuem cerca de 50 a 60 metros de profundidade, e não 
seguem um padrão de construção. Os períodos sazonais foram definidos de acordo com o balanço hídrico das séries históricas do clima de São Luís - MA do ano de 2013 (Agritempo, 2009), sendo os períodos de transição seco/chuvoso (P-S/C), janeiro; chuvoso (P-C), abril; transição chuvoso/seco (P-C/S), julho; e seco (P-S), outubro. Foi monitorada a qualidade da água quanto aos parâmetros físico-químicos, colimétricos e parasitológicos.

Os locais de coleta foram georeferenciados, e foram registradas as características dos elementos que compõem o saneamento rural. Os quatro poços monitorados foram: P1-1A (região ao norte, possui um abatedouro); P3-8A (região a oeste, possui uma horta); P4-13A (região ao centro, área residencial predominante) e P6-20A (região ao sul, área residencial predominante) - Dois poços estavam inativos (P2 e P5). O tempo de coleta e a realização das análises colimétricas não excederam as 24 horas (APHA, 1998), e não foram necessárias diluições das amostras. Foram considerados como referência os parâmetros de potabilidade estabelecido na Portaria do MS No. 2914/2011 (Brasil, 2011). Os parâmetros analisados foram os físico-químicos: turbidez, cor aparente, condutividade, $\mathrm{pH}$, cloro, sólidos totais, dureza total, alcalinidade, cloretos, salinidade e oxigênio dissolvido; e os parâmetros bacteriológicos para coliformes totais (CT) e Escherichia coli (EC), sendo utilizado o método do substrato cromogênico Colilert ${ }^{\circledR}$ Quanti-Tray 2000 da IDEXX, segundo normas descritas pelo fabricante. Os dados, porém, foram convertidos para Unidade Formadora de Colônia (UFC) por mililitro, baseados nos dados descritos em Gronewold e Wolpert (2008). Para as análises parasitológicas, dois mil litros de água dos poços foram filtradas em refil poroso coberto com manta de estercelulose de $47 \mu \mathrm{m}$ conforme descrito em Handam (2016), para retenção do material particulado. Esses elementos filtrantes foram desfeitos e foram utilizadas as técnicas de Lutz (1919) e de Baermann (1917) adaptadas (Amaral et al., 2015) para análise das três lâminas que foram preparadas para cada amostra e examinados à 100X e 400X de aumento, conforme descrito em Amaral et al. (2015).

\section{RESULTADOS E DISCUSSÃO}

Para o parâmetro físico de avaliação do nível de turbidez, que se deve à presença de material sólido em suspensão, causando um aspecto estético indesejável (APHA, 1998), o valor máximo permitido (VMP) de referência na água de consumo apresentou-se satisfatório em todos os períodos, o que garante a qualidade da água (Tabela 1). Esse parâmetro possui grande relevância devido à dificuldade na desinfecção pela proteção conferida pelas partículas em suspensão, impedindo o contato direto dos agentes patogênicos aos desinfetantes (Brasil, 2011).

A cor aparente da água, que é uma característica associada a substâncias dissolvidas ou em suspensão (Pinto et al., 2015), teve variação média nos quatro períodos sazonais (P-S/C, $\mathrm{P}-\mathrm{C}, \mathrm{P}-\mathrm{C} / \mathrm{S}$ e $\mathrm{P}-\mathrm{S})$ em conformidade com a legislação, sendo que no período de transição seco-chuvoso (P-S/C) e chuvoso-seco (P-C/S) apresentaram-se valores em média de $5,02 \pm 2,02$ e 12,64 $\pm 1,10$, respectivamente (Tabela 1). Este parâmetro, embora não implique risco à saúde, pode provocar rejeição pelo consumidor, e o inconveniente de manchar roupas, vasilhames de alimentos, pias, etc (Brasil, 2011).

Embora a Portaria No. 2.914/2011 não faça referências ao parâmetro físico da condutividade elétrica (CE), Chapman e Kimstach (1996) descreveram que a CE em águas doces varia de 10 a $1000 \mu \mathrm{S} \mathrm{cm}^{-1}$, e indicaram este parâmetro como um indicador da presença de material orgânico recente introduzido nas águas. Quando a condutividade for igual ou superior a $1000 \mu \mathrm{S} \mathrm{cm}^{-1}$, as águas passam a ficar salobras ou podem estar poluídas. Segundo Richards (1954), os limites para a classe de salinidade $\mathrm{C} 1$ ficaria entre $0-250 \mu \mathrm{S} \mathrm{cm}^{-1}$, sendo descrita como água com baixa salinidade, podendo ser utilizada para irrigação nas culturas, em quase todos os tipos de solos. Os valores medidos para CE nas águas dos poços foram 
baixos, com variação média mínima de $130,9 \pm 39,75$ para o período chuvoso (P-C) e máxima de 168,3 \pm 68,29 para o período de transição C/S (P-C/S) (Tabela 1).

$\mathrm{O}$ parâmetro do $\mathrm{pH}$ foi dosado por representar íons hidrogênio $\mathrm{H}^{+}$e dar indicação sobre a condição de acidez, neutralidade ou alcalinidade da água, sendo os valores abaixo de 7 (sete) considerados ácidos, 7 (sete), neutro e acima de 7 (sete). alcalino ou básico. Para fins de consumo humano, a Portaria do MS No. 2914/2011 define os padrões de potabilidade da água, como valor mínimo permitido de 6,0 (seis) e o valor máximo permitido de 9,5 (nove e meio). Valores baixos de $\mathrm{pH}$ podem gerar problemas como: irritação nos olhos, na pele e membranas/mucosas. $\mathrm{O}$ pH baixo ou muito elevado também pode afetar o desempenho do tratamento de desinfecção da água. Nas águas naturais, as variações destes parâmetros são ocasionadas geralmente pelo consumo e/ou produção de dióxido de carbono $\left(\mathrm{CO}_{2}\right)$, realizados por organismos fotossintetizadores e pelos fenômenos de respiração/fermentação de todos os organismos presentes na massa de água, produzindo ácidos orgânicos fracos. Nas amostras monitoradas nos quatros períodos: P-S/C, P-C, P-C/S e P-S a variação media foi de $5,35 \pm 0.51 ; 5,81 \pm 0.60 ; 5,54 \pm 0.56$ e 5,69 \pm 0.87 , respectivamente (Tabela 1), portanto abaixo da faixa recomendada pela legislação, indicando necessidade de tratamento.

As amostras apresentaram ausência de cloro residual livre (CRL), o que pode possibilitar a presença de patógenos na água (Tabela 1). Uma concentração de $0,5 \mathrm{mg} \mathrm{L}^{-1}$ de CRL na água, depois de 30 minutos de contato garante a desinfecção satisfatória. $\mathrm{O}$ teor de cloro ativo que permanece após a desinfecção (cloração) da água, permite que a qualidade microbiológica seja mantida em condições de consumo. Para águas potáveis, segundo o Art. $34^{\circ}$, Portaria do MS No. 2914/2011, é obrigatória a manutenção de no mínimo $0,2 \mathrm{mg} \mathrm{L}^{-1}$ de CLR ou $2 \mathrm{mg} \mathrm{L}^{-1}$ de cloro residual combinado, ou de $0,2 \mathrm{mg} \mathrm{L}^{-1}$ de dióxido de cloro em toda extensão do sistema de distribuição (reservatório ou rede).

Tabela 1. Variação média dos parâmetros físico-químicos dos períodos de transição seco-chuvoso (P-S/C), chuvoso (P-C), transição chuvoso-seco (P-C/S) e seco (P-S).

\begin{tabular}{|c|c|c|c|c|c|}
\hline Parâmetros & $\mathrm{P}-\mathrm{S} / \mathrm{C}$ & $\mathrm{P}-\mathrm{C}$ & $\mathrm{P}-\mathrm{C} / \mathrm{S}$ & $\mathrm{P}-\mathrm{S}$ & VMP \\
\hline Físicos & $\mathrm{X} \pm \mathrm{DP}$ & $\mathrm{X} \pm \mathrm{DP}$ & $\mathrm{X} \pm \mathrm{DP}$ & $\mathrm{X} \pm \mathrm{DP}$ & \\
\hline Temperatura da água $\left({ }^{\circ} \mathrm{C}\right)$ & $29 \pm 0,33$ & $29 \pm 0,82$ & $29,4 \pm 0,82$ & $29,8 \pm 0,87$ & - \\
\hline Turbidez (NTU) & $0,90 \pm 0,33$ & $0,79 \pm 0,34$ & $0,53 \pm 0,18$ & $0,53 \pm 0,19$ & $5^{(1)}$ \\
\hline Cor Aparente (uH) & $5,02 \pm 2,02$ & $9,65 \pm 2,38$ & $12,64 \pm 1,10$ & $9,17 \pm 4,15$ & $15^{(1)}$ \\
\hline $\begin{array}{l}\text { Condutividade elétrica ( } \mu \mathrm{S} \\
\mathrm{cm}^{-1} \text { ) }\end{array}$ & $148,7 \pm 71,21$ & $130,9 \pm 39,75$ & $168,3 \pm 68,29$ & $163 \pm 78,98$ & ND \\
\hline \multicolumn{6}{|l|}{ Químicos } \\
\hline $\mathrm{pH}$ & $5,35 \pm 0,51$ & $5,81 \pm 0,60$ & $5,54 \pm 0,56$ & $5,69 \pm 0,87$ & $\begin{array}{l}6,0-9,5^{(1)} \\
6,0-9,0^{(2)}\end{array}$ \\
\hline $\begin{array}{l}\text { Cloro residual livre } \\
\left(\mathrm{mg} \mathrm{L}^{-1}\right)\end{array}$ & Ausente & Ausente & Ausente & Ausente & $2^{(1)}$ \\
\hline $\begin{array}{l}\text { Sólidos Totais Dissolvidos } \\
\text { (STD) }\left(\mathrm{mg} \mathrm{L}^{-1}\right)\end{array}$ & $79,4 \pm 32,61$ & $65,2 \pm 16,73$ & $73,3 \pm 31,83$ & $99,5 \pm 46,06$ & $1000^{(1)(2)}$ \\
\hline $\begin{array}{l}\text { Dureza Total } \\
\left(\mathrm{mg} \mathrm{L}^{-1} \mathrm{CaCO}_{3}\right)\end{array}$ & $122,80 \pm 96,87$ & $105,48 \pm 48,72$ & $114,16 \pm 82,82$ & $89,32 \pm 54,47$ & $500^{(1)}$ \\
\hline $\begin{array}{l}\text { Alcalinidade Total } \\
\left(\mathrm{mg} \mathrm{L}^{-1} \mathrm{CaCO}_{3}\right)\end{array}$ & $38,51 \pm 32,08$ & $22,9 \pm 16,40$ & $38,6 \pm 29,19$ & $53,44 \pm 44,30$ & ND \\
\hline Cloretos $\left(\mathrm{mg} \mathrm{L}^{-1}\right)$ & $8,39 \pm 1,43$ & $6,73 \pm 1,05$ & $6,92 \pm 0,81$ & $7,09 \pm 1,38$ & $250^{(1)(2)}$ \\
\hline
\end{tabular}

Nota: ${ }^{(1)}$ Portaria N $^{\circ} 2.914$ de 12 de dezembro de 2011 - Ministério da Saúde; ${ }^{(2)}$ Resolução CONAMA N ${ }^{\circ} 396,3$ de abril de 2008 - Água Subterrânea; ND = Não descrito na legislação; X = média; DP = desvio padrão. 
A Portaria $\mathrm{n}^{\circ}$ 2.914/2011 do MS também define que a quantidade de sólidos totais dissolvidos (STD) encontrada na água potável não deve exceder $1000 \mathrm{mg} \mathrm{L}^{-1}$. A Tabela 1 mostra os resultados para os STD, sendo que todas as amostras encontravam-se dentro do permitido para consumo humano com variação mínima de $65,2 \pm 16,73$ no período chuvoso, e máxima de 99,5 $\pm 46,06$ no período seco. Portanto, os poços analisados apresentaram valores de STD aceitáveis. Segundo Medeiros Filho (2009), os sólidos totais dissolvidos na água podem causar alterações de gosto e problema de corrosão na rede se for muito acima do valor máximo permitido.

Em relação à dureza total da água, as águas de todos os poços estudados apresentaram-se satisfatoriamente dentro do limite permitido - ficaram abaixo do VMP - conforme apresentado na Tabela 1. Este parâmetro refere-se, principalmente, à concentração de íons de cálcio e magnésio em solução, formando precipitados, sendo expressa como $500 \mathrm{mg} \mathrm{L}^{-1}$ de $\mathrm{CaCO}_{3} . \mathrm{A}$ dureza pode causar sabor desagradável à água, formação de biofilmes, efeito laxativo, e influenciar a capacidade de formar espuma por sabão e detergente. A dureza é dividida em: temporária e permanente. A dureza temporária é também conhecida por "dureza de bicarbonatos". Os bicarbonatos de cálcio e de magnésio, pela ação de substâncias alcalinas, se transformam em carbonatos, que são insolúveis. A dureza permanente deve-se à presença de sulfatos ou cloretos de cálcio ou magnésio, que reagem com as substâncias alcalinas, formando também os carbonatos (Medeiros Filho, 2009).

A alcalinidade da água é representada pela presença dos íons hidróxidos $\left(\mathrm{OH}^{-}\right)$, carbonatos $\left(\mathrm{CO}_{3}{ }^{2-}\right)$ e bicarbonatos $\left(\mathrm{HCO}_{3}{ }^{-}\right)$. Com maior frequência, a alcalinidade da água é devida a bicarbonatos produzidos pela ação do gás carbônico dissolvido na água sobre as rochas calcárias. A Portaria do $\mathrm{MS} \mathrm{n}^{\circ}$ 2.914/2011 não faz referências a esse parâmetro e não há especificações na legislação brasileira estabelecendo os limites de alcalinidade em água. A maioria das águas naturais apresentam valores de alcalinidade na faixa de 30 a $500 \mathrm{mg} \mathrm{L}^{-1} \mathrm{de}$ $\mathrm{CaCO}_{3}$. Os resultados das amostras das águas dos poços tubulares durante os períodos da pesquisa variaram de 22,9 $\pm 16,40$ (período chuvoso) a 53,44 \pm 44,30 (período seco), sendo que a alcalinidade predominante foi a de bicarbonatos (Tabela 1). Os cloretos podem estar presentes tanto em águas brutas quanto em águas tratadas, dependendo do tipo de tratamento. Concentrações altas de cloretos podem restringir o uso da água em razão do sabor salgado que conferem a mesma, e pelo efeito laxativo que podem provocar. Altas concentrações de cloreto podem significar infiltração de águas residuais e excesso de urina de pessoas e animais. Os métodos convencionais de tratamento de água não removem cloretos; a sua remoção é feita por desmineralização (deionização) ou evaporação (FUNASA, 2006). A portaria do MS n ${ }^{\circ}$ 2914/2011 estabelece o teor de $250 \mathrm{mg} \mathrm{L}^{-1}$ como o valor máximo permitido (VMP) para água potável. Os resultados encontrados nas águas dos poços tubulares não comprometem a sua qualidade, pois os valores estão abaixo do valor máximo permitido. Conforme os resultados, o período de transição seco-chuvoso apresentou maior valor médio de $8,39 \pm 1,43$, e menor no período chuvoso, 6,73 \pm 1,05 (Tabela 1). Esses dados corroboram com o descrito na literatura, que as águas subterrâneas apresentam, geralmente, teores de cloretos inferiores a $100 \mathrm{mg} \mathrm{L}^{-1}$ (Fernandes et al., 2005).

Os parâmetros microbiológicos analisados para a água de consumo humano foram os referentes às bactérias do grupo coliforme, tomando como padrão a presença ou ausência. Os indicadores avaliados foram os coliformes totais (CT), que por sua vez, são bactérias Gram negativas que podem ser encontradas no solo, e em matéria vegetal em decomposição, e não se correlacionam necessariamente com origem fecal, contudo são mais resistentes na água que as bactérias patogênicas de origem intestinal (APHA, 1998). O outro parâmetro de maior relevância trata-se dos níveis de Escherichia coli (EC), principal indicador de contaminação fecal, por ser uma bactéria presente no trato intestinal humano e em animais homeotérmicos, descrito nas legislações de vários países (Sotero-Martins et al., 2013; Felski et al., 2008; 
Cunha et al., 2012). Sendo assim os resultados dos níveis colimétricos para a água dos poços foram analisados considerando a ausência desses dois parâmetros, como especificado na Portaria No. 2.914 do MS, que é o órgão que trata da saúde. Embora a Resolução CONAMA 396/2008 seja específica para águas subterrâneas, ela é mais permissiva. Desta forma, o poço P6 apresentou valores para CT em três das quatro estações monitoradas, sendo elas: estação de transição seco-chuvosa (P-S/C), transição chuvoso-seca (P-C/S) e chuvosa (P-C). Portanto, foi o poço que apresentou mais vezes água com qualidade imprópria para consumo humano. $\mathrm{O}$ poço $\mathrm{P} 3$ esteve com água imprópria em duas estações monitoradas, sendo elas no $\mathrm{P}-\mathrm{S} / \mathrm{C}$ e P-S. Enquanto que os poços P1 e P4 somente apresentaram dados impróprios em uma estação (Figura 1). Nenhum poço na estação chuvosa apresentou níveis de coliformes detectáveis, provavelmente devido à diluição provocada pela grande quantidade de chuvas que ocorreu no período que antecedeu a coleta. Destaca-se que nos dias anteriores a coleta da amostra, a precipitação média foi de $25,1 \mathrm{~mm}$ (Figura 2), portanto este é o período sazonal de menor risco para uso da água sem tratamento. Apesar de terem sido encontrados níveis de CT nas águas em alguns períodos, não foram detectados EC em nenhuma das amostras dos poços, portanto o risco associado à presença de esgoto sanitário com contaminação recente na água dos poços foi menor. Mas foi possível detectar que houve períodos de maior risco ao consumo das águas e que as regiões onde ficam os poços P6 (área que predomina residências) e P3 (área que possui horta) são as mais vulneráveis (Figura 1), o que torna inviável a utilização dessa água para consumo humano sem que antes passe por um processo de desinfecção ou filtração, com vistas a eliminar as bactérias presentes, uma vez que a presença desses organismos pode acarretar problemas de saúde para a população que consome a água contaminada (Gonçalves et al., 2003; Archer et al., 1997).

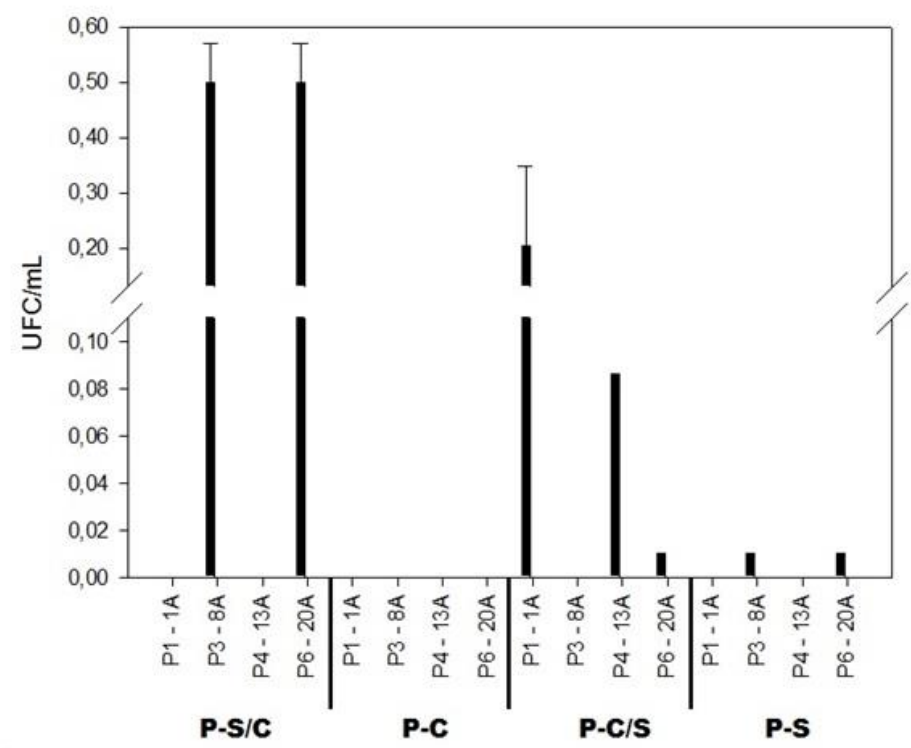

Figura 1. Níveis de coliformes encontrados na água dos poços tubulares ativos da comunidade de Cinturão Verde, nas quatro estações do ano. níveis de CT; $\square$ - níveis de EC.

Quanto às análises parasitológicas, somente foi detectada a presença de larvas de nematóide (tipo filarióide) em amostra de água do poço P4 (área predominantemente residencial) durante o período seco. De acordo com Carli (2001), essa forma infectante é capaz de penetrar na pele ou mucosas, podendo evoluir no interior do hospedeiro, ocasionando os casos de auto-infecção interna. Considerando que alguns parasitas passam 
parte do seu ciclo de desenvolvimento no solo, como no caso do Ascaris sp., a ocorrência de geohelmintos em solos contaminados por dejetos de animais constitui um problema de saúde pública, pois pode contaminar os mananciais. Devido à peculiaridade do ciclo biológico de seus agentes etiológicos, e agregado à proximidade existente entre seres humanos e animais de estimação, são considerados agentes de doenças relativamente importantes, sob a ótica epidemiológica (Rey, 2008).

Também foi feita avaliação dos sistemas existentes que compõem o saneamento rural, sendo constatada a precariedade dos serviços de saneamento básico, o que confere maior vulnerabilidade das fontes de abastecimento de água. Os motivos dessa vulnerabilidade são: a predominância de sistemas individuais inadequados da disposição final dos esgotos domésticos, dos resíduos da agricultura e domiciliares, e da criação de animais em uma proximidade inadequada em relação aos poços, e o fato das águas servidas serem lançadas a céu aberto nas ruas sem pavimentação, ocasionando infiltração, o que pode contaminar as águas subterrâneas. Os reflexos das ações de saneamento ou de sua carência são notórios sobre o meio ambiente, em particular sobre os recursos hídricos (Heller e Castro, 2007). E ainda que a comunidade seja provida de um sistema de coleta de resíduos sólidos, os mesmos são dispostos de forma inadequada podendo contribuir com percolação do lixiviado devido a decomposição da matéria orgânica e, consequentemente, uma provável contaminação do lençol freático, gerando impactos diretos na qualidade de vida e saúde humana (Santiago et al., 2001). Foi observado que alguns poços ativos possuíam dispositivo de proteção sanitária com estrutura coberta e canalização dotada de bombas submersas que recalcam água e distribuem por meio de canos, porém a canalização abastece diretamente apenas as residências próximas. $\mathrm{O}$ fator de maior agravo foi à presença de currais e chiqueiros na proximidade dos poços construídos de forma rudimentar, com risco dos dejetos dos animais estarem dispostos diretamente sobre o solo, contaminando o mesmo e provavelmente a água subterrânea.

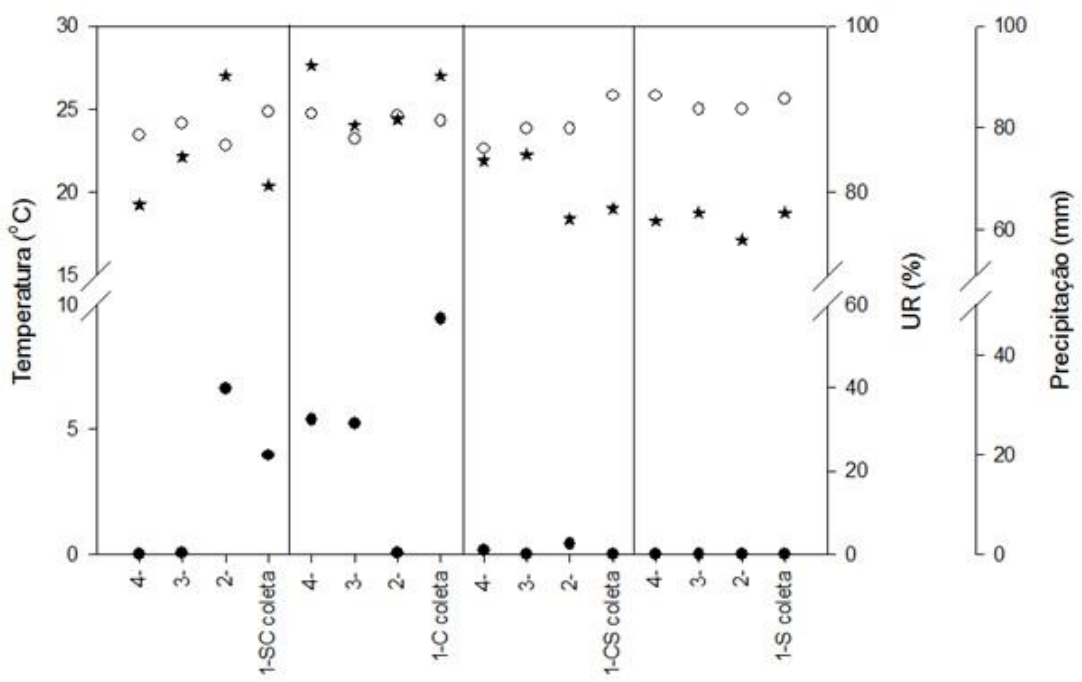

Figura 2. Dados meteorológicos relacionados com os dias de coleta.

Nota: ${ }^{\circ}$ - Temperatura do ar $\left({ }^{\circ} \mathrm{C}\right)$; $\star$-Umidade relativa do ar (\%); - Precipitação de chuva (mm). Fonte de dados históricos: INMET, 2014. SC - período de transição seco-chuvoso; C - período chuvoso; CS - período de transição chuvoso-seco; $\mathrm{S}$ - período seco. 


\section{CONCLUSÕES}

A Comunidade do Cinturão Verde não dispõe dos serviços de saneamento básico, está desprovida de meios adequados para dispor os dejetos de sistema de coleta de resíduos sólidos, e de fontes de abastecimento de água potável, que precisam ser monitoradas e tratadas, principalmente nos períodos sazonais de maior risco. Prevalece o sistema individual de disposição final de esgoto doméstico, com uso de fossas negras próximas aos mananciais. As análises físico-químicas, colimétricas e parasitológicas evidenciaram que as fontes de abastecimento de água, P6, P3, P1 e P4, estavam inadequadas, e que as águas precisam passar por controle de qualidade, pois a ausência de saneamento é um fator que concorre para a contaminação das águas subterrâneas. A contaminação das águas coloca a população consumidora exposta a diversos riscos à saúde por doenças de veiculação hídrica. $\mathrm{O}$ risco à saúde da população seria diminuído se houvesse monitoramento da qualidade das águas dos poços e tratamento nos períodos de vulnerabilidade. Tal constatação evidenciou a importância do saneamento básico, principalmente dos serviços de água e de esgotos, indispensáveis à promoção da saúde pública.

\section{AGRADECIMENTOS}

Projeto financiado pelo Conselho Nacional para o Desenvolvimento Científico e Tecnológico (CNPq), CT-Hidro n. 577.432/2008-7. Agradecemos ao Instituto Federal de Educação, Ciência e Tecnologia do Maranhão - IFMA- São Luís - Campus Maracanã pelo apoio para os processos de coleta, à Secretaria do Meio Ambiente do Estado (SEMA) por ceder o Laboratório de Microbiologia para as análises colimétricas do solo e da água, à Universidade Estadual do Maranhão (UEMA) pela colaboração nas análises físicas do solo, e ao Antônio José Jaime Maia e Adriano Moura Rocha pelo acompanhamento em etapas do projeto.

\section{REFERÊNCIAS}

AGRITEMPO. Sistema de Monitoramento Agrometeorológico Dados meteorológicos: Maranhão, estação meteorológica São Luís. 2009. Disponível em: http://www.agritempo.gov.br/agroclima/sumario?uf=MA. Acesso em: 16 abr. 2014.

AISSE, M. M.; CORAUCCI FILHO, B.; ANDRADE NETO, C. O.; JURGENSEN, D.; LAPOLLI, F. R.; MELO, H. M. S.; et al. Cloração e descloração. In: PROSAB. Desinfecção de efluentes sanitários, remoção de organismos patógenos e substâncias nocivas: aplicações para fins produtivos como agricultura, aquicultura e hidroponia. Rio de Janeiro, 2003. p. 113-168.

AMARAL, L. A.; NADER FILHO, A.; ROSSI JUNIOR, O. D.; FERREIRA, F. L. A.; BARROS, L. S. S. Água de consumo humano como fatos de risco à saúde em propriedades rurais. Revista de Saúde Pública, v. 37, p. 510-514. 2003. http://dx.doi.org/10.1590/S0034-89102003000400017

AMARAL, L. S.; DUARTE, A. N.; SILVA, V. L.; PINNA, L. C. L.; SOTERO-MARTINS, A. Parasitological indicators of contamination at sando $\mathrm{f}$ beach and monitoring by traditional methods and immunoenzymatic assay. Brazilian Journal of Biosystems Engineering, v. 9, n. 4, p. 304-311, 2015. http://dx.doi.org/10.18011/bioeng2015v9n4p304-311 
AMERICAN PUBLIC HEALTH ASSOCIATION - APHA. Standard methods for the examination of water and wastewater. Washington, 1998.

ARCHER, A.; FISCHER, E.; TURNHEIN, R.; MANOR, Y. Ecologically, friendly, wasterwater disinfection techniques. Water Research, v. 31, n.6, p. 1398-1404, 1997. http://dx.doi.org/10.1016/S0043-1354(96)00000-0

BAERMANN, G. A simple method for the detection of Ankylostomum (nematode) larvae in soil tests. Mededeel mit h Geneesk, Lab Weltvreden Feestbubdel, p. 41-47, 1917.

BRASIL. Decreto $\mathrm{n}^{\circ} 7.217$ de 21 de junho de 2010. Regulamenta a Lei ${ }^{\circ} 11.445$, de 5 de janeiro de 2007, que estabelece diretrizes nacionais para o saneamento básico, e dá outras providências. Diário Oficial [da] União, Brasília, 21 jun. 2010.

BRASIL. Ministério da Saúde. Secretaria de Vigilância em Saúde. Vigilância e controle da qualidade da água para consumo humano. Brasília, 2006.

BRASIL. Ministério da Saúde. Gabinete do Ministro. Portaria no 2914, de 12 de dezembro de 2011, que dispõe sobre os procedimentos de controle e de vigilância da qualidade da água para consumo humano e seu padrão de potabilidade. Diário Oficial [da] União, 14 dez. 2011, Seção 1, p. 39-46.

CALDEIRA, J. V. Vulnerabilidade social associada aos efeitos das mudanças climáticas na saúde pública. 2014. 150f. Dissertação (Mestrado em Saúde Pública e Meio Ambiente) - Escola Nacional de Saúde Pública, Fundação Oswaldo Cruz, Rio de Janeiro, 2014.

CARLI, G. A. Parasitos intestinais. In: CARLI, G. A. (Org.). Parasitologia clínica: seleção de métodos e técnicas de laboratório para diagnóstico das parasitoses humanas. Rio de Janeiro: Atheneu, 2001. p. 1-162.

CHAPMAN, D.; KIMSTACH, V. Selection of water quality variables. In: CHAPMAN, D. (Ed.). Water quality assessments: a guide to the use of biota, sediments and water in environmental monitoring. Cambridge: University Press, 1996. p. 59-126.

COSTA, C. C.; GUILHOTO, J. J. M. Saneamento rural no Brasil: impacto da fossa séptica biodigestor. Engenharia Sanitária e Ambiental, Ed. Especial, p. 51-60, 2014. http://dx.doi.org/10.1590/S1413-41522014019010000171

CUNHA, H. F. A.; LIMA, D. C. I.; BRITO, P. N. F.; CUNHA, A. C.; SILVEIRA JUNIOR, A. M.; BRITO, D. C. Qualidade físico-química e microbiológica de água mineral e padrões da legislação. Revista Ambiente \& Água, v. 79, n. 3, p. 155-165, 2012. http://dx.doi.org/10.4136/ambi-agua.908

CENTRO DE VIGILÂNCIA EPIDEMIOLÓGICA "PROF. ALEXANDRE VRANJAC" CVE. Divisão de Doenças de Transmissão Hídrica e Alimentar - DDTHA. Doenças relacionadas à água ou de transmissão hídrica: perguntas e repostas e dados estatísticos. 2009. Disponível em: ftp://ftp.cve.saude.sp.gov.br/doc_tec/hidrica/doc/ DTA09_pergresp.pdf. Acesso em: abr. 2014.

DANIEL, L. A. Água e doenças. In: DANIEL, L. A. (Coord.) Processos de desinfecção e desinfetantes alternativos na produção de água potável. São Carlos: PROSAB, 2001. p. $1-23$ 
FELSKI, G.; ANAISSI, F. J.; QUINÁIA, S. P. Avaliação da qualidade da água consumida pela população do município de Guarapuava, Paraná. Revista Eletrônica Lato Sensu, v. 3, n. 1, p. 1-25, 2008.

FERNANDES, M. A. B.; SANTIAGO, M. M. F.; GOMES, D. F.; MENDES FILHO, J.; FRISCKORN, H.; LIMA, J. O. G. A origem dos cloretos nas águas subterrâneas na Chapada do Apodi - Ceará. Águas Subterrâneas, v. 19, n. 1, p. 25-34, 2005.

FUNDAÇÃO NACIONAL DE SAÚDE - FUNASA (Brasil). Manual prático de análise de água. 2. ed., rev. Brasília, 2006.

GONÇALVES, R. F.; JORDÃO, E. P.; SOBRINHO, P. A. Introdução. In: PROSAB. Desinfecção de efluentes sanitários, remoção de organismos patogênicos e substancias nocivas: aplicações para fins produtivos como agricultura, aquicultura e hidroponica. Rio de Janeiro, 2003. p. 1-26.

GRONEWOLD, A. D.; WOLPERT, R. L. Modeling the relationship between most probable number (MNP) and colony-forming unit (CFU) estimates of fecal coliform

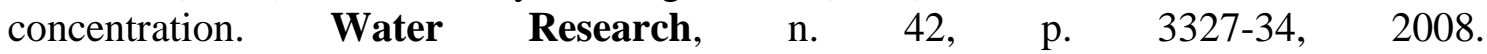
http://dx.doi.org/10.1016/j.watres.2008.04.011

HAGER, F. P. V. Águas subterrâneas no direito público. 2007. 15f. Monografia (Especialização em Direito Público) - Faculdade Metropolitana de Belo Horizonte, Belo Horizonte, 2007.

HANDAM, N. B. Condições sanitárias da água residencial, do solo peridomiciliar e dos rios das comunidades do território de Manguinhos, RJ. 2016. Dissertação (Mestrado em Saúde Pública e Meio Ambiente) - Escola Nacional de Saúde Pública, Fundação Oswaldo Cruz, Rio de Janeiro, 2016.

HELlER, L.; PÁDUA, V. L. (Orgs.). Abastecimento de água para consumo humano. 2. ed. Belo Horizonte: Ed. UFMG, 2006. 428 p.

HELlER, L.; CASTRO, J. E. Política pública de saneamento: apontamentos teóricoconceituais. Engenharia Sanitária e Ambiental, v. 12, n. 3, p. 284-295, 2007.

HERRÁIZ, A. S. La importancia de las aguas subterráneas. La Revista de la Real Academia de Ciencias Exactas, Físicas y Naturales, v. 103, n. 1, p. 97-114, 2009.

LUTZ, A. O Schistosoma mansoni e a schistosomatose segundo observações feitas no Brasil. Memórias do Instituto Oswaldo Cruz, v. 11, p. 121-155, 1919.

MEDEIROS FILHO, C. F. Noções sobre tratamento de água. In: Abastecimento de água. 2009. Disponível em: http://www.dec.ufcg.edu.br/saneamento/Agua.html. Acesso em: dez 2016.

PINTO, C. M. A.; ARAUJO, N. A.; SILVA JÚNIOR, D. F. Diagnóstico preliminar do saneamento rural na comunidade de Engenho Velho no Município de João Pessoa/PB. Revista Ambiental, v. 1, n. 1, p. 26-36, 2015.

REY, L. Parasitologia. 4. ed. Rio de Janeiro: Guanabara Koogan, 2008. p. 1-25.

RICHARDS, L. A. (Ed.). Diagnosis and improvement of saline and alkali soils. Washington: U.S. Government Printing Office, 1954. 
SANTIAGO, M. F.; FRISCHKORN, H.; SALES NETO, P.; MENDES FILHO, J. The recharge mechanisms in an alluvial aquifer zone in northeast Brazil. Ground Water, n. 39, v. 1, p. 18 - 23, 2001. http://dx.doi.org/10.1111/j.1745-6584.2001.tb00347.x

SOTERO-MARTINS, A.; DUARTE, A. N.; CARVAJAL, E.; SARQUIS, M. I. M.; FERNANDES, O. C. Controle da qualidade microbiológica e parasitária em áreas de recreação. Gestão \& Saúde, v. 4, n. 3, p. 1075-1092, 2013. http://www.arca.fiocruz.br/handle/icict/10709

TCHOBANOGLOUS, G.; BURTON, F. L.; STENSEL, H. D. Wasterwater treatment. In: Wastewater engineering: treatment and reuse. Boston: Metcalf \& Eddy Inc., 2003. p. 10-20.

VON SPERLING, M.; JORDÃO, E. P.; KATO, M. T.; SOBRINHO, P. A.; BASTOS, R. K. X.; PIVELLI, R. Lagoas de estabilização. In: PROSAB. Desinfecção de efluentes patógenos e substâncias nocivas: aplicações para fins produtivos como agricultura, aquicultura e hidroponia. Rio de Janeiro, 2003. p. 276-336. 